\title{
Flow-field Analysis of Isobaric Combustion using Multiple Injectors in an Optical Accessible Diesel Engine
}

\author{
Niraj Panthi ${ }^{1}$, Harsh Goyal ${ }^{1}$, Moez Ben Houidi ${ }^{1}$, Abdullah S. AlRamadan² ${ }^{2}$ Jihad Badra $^{2}$, Gaetano \\ Magnotti $^{1}$
}

\author{
${ }^{1}$ King Abdullah University of Science and Technology, Saudi Arabia \\ ${ }^{2}$ Transport Technologies Division, R\&DC, Saudi Aramco, Dhahran, Saudi Arabia
}

Copyright $\odot 2021$ SAE International

\begin{abstract}
Isobaric combustion has shown the potential of improving engine efficiency by lowering the heat transfer losses. Previous studies have achieved isobaric combustion through multiple injections from a single central injector, controlling injection timing and duration of the injection. In this study, we employed three injectors, i.e. one centrally mounted (C) on the cylinder head and two side-injectors (S), slantmounted on cylinder head protruding their nozzle tip near piston-bowl to achieve the isobaric combustion. This study visualized the flame development of isobaric combustion, linking flow-field details to the observed trends in engine efficiency and soot emissions. The experiments were conducted in an optically accessible single-cylinder heavy-duty diesel engine using $\mathrm{n}$-heptane as fuel. Isobaric combustion, with a 50 bar peak pressure, was achieved with three different injection strategies, i.e. $(\mathrm{C}+\mathrm{S}),(\mathrm{S}+\mathrm{C})$, and $(\mathrm{S}+\mathrm{S})$. Bottom-view high-speed soot luminosity images were recorded at a frame rate of $20 \mathrm{kHz}$ for all cases, together with pressure traces. Flame image velocimetry (FIV) analysis was performed on the high-speed soot luminosity images to obtain a qualitative description of the flow-field obtained for the three injection strategies. Distinctive vortex structures were evident from the FIV analysis and that can be attributed to strong flame-wall and flameflame interactions. For the $\mathrm{C}+\mathrm{S}$ and $\mathrm{S}+\mathrm{S}$ injection strategies, the distinct large vortex structures were found near the bowl-wall while for the $\mathrm{S}+\mathrm{C}$ case, vortex structures are less prominent. The large vortex structures close to the cylinder walls contribute to lower gross indicated efficiency and higher soot level intensity of the $\mathrm{C}+\mathrm{S}$ and $\mathrm{S}+\mathrm{S}$ cases, compared to the $\mathrm{S}+\mathrm{C}$ configuration.
\end{abstract}

\section{Introduction}

Diesel compression ignition (CI) engines, in which ignition of fuel is initiated instantaneously upon injection towards compressed incylinder air, have been widely used in the transportation sector particularly for heavy-duty vehicles. However, due to limited fuel and air mixing, the locally fuel-rich reaction zones co-existed with the hot stoichiometric regimes at the jet periphery [1], which led to increased emissions of particulate matter (PM) and nitric oxides $\left(\mathrm{NO}_{\mathrm{x}}\right)$, respectively. Although many efforts have been made to reduce these emissions in recent years, further reductions are required to meet the ever-increasingly stringent emission legislations [2], coupled with targets to achieve higher engine efficiency.

To meet the combined needs of further emissions reduction and improved efficiency, many alternative concepts of CI combustion such as homogeneous charge compression ignition (HCCI) $[3,4]$, reactivity controlled compression ignition (RCCI) [5], and partially premixed combustion (PPC) [6-8] have been pursued by the combustion engine researchers around the globe. Most of these concepts are based on isochoric combustion utilizing the principle of dilute premixed or partially premixed combustion to reduce emissions and improve engine efficiency. However, there are certain challenges such as Page 1 of 11 combustion phasing control for HCCI combustion [9], impractical utilization of two different fuels for RCCI combustion, and achieving a high-load limit for PPC combustion [10]. Furthermore, significant losses are incurred during the transformation of thermodynamic efficiency to brake thermal efficiency (BTE) [11], and hence these combustion concepts require further development to achieve the desired target of higher engine efficiency.

Combustion concepts based on isobaric combustion [11-13] have the potential to achieve high efficiency and low emissions while overcoming some of the limitations of HCCI, RCCI, and PPC. In previous studies $[11,12,14]$, the isobaric combustion is achieved by using multiple injections from a single central injector and the results are compared with conventional diesel combustion (CDC). When comparing combustion cycles at the same peak cylinder pressure (PCP), isobaric combustion showed similar efficiencies to CDC, lower $\mathrm{NO}_{\mathrm{x}}$ levels and heat transfer losses, higher exhaust energy but also increased soot emissions. The controllability of injection timing and duration of multiple injections in isobaric combustion results in a slower heat release rate meaning longer combustion duration than CDC. Furthermore, increased intake air pressure to achieve higher PCP for isobaric combustion results in higher gross indicated efficiency and exhaust energy fraction; however, lesser heat transfer losses to the cylinder walls than CDC [11]. The latter advantages make the isobaric combustion suitable for split-cycle concepts such as the double compression expansion engines (DCEE) concept [15-17], which has the potential to achieve BTE up to $56 \%$. Numerical and experimental work has shown that the use of multiple injectors can reduce the soot emission, while still achieving the desired isobaric combustion $[13,18,19]$. The advantage of multiple injectors provides flexibility in the temporal and spatial control of fuel sprays avoiding the injection into the burnt zone and hence reducing the soot emissions along with enhanced mixing.

Previous optical studies on isobaric combustion have employed multiple injections from a central injector [20,21] only and very few experimental studies have been conducted using multiple injectors $[13,18]$. Besides, flow-field structures and their influence on engine performance and emissions are not addressed in previous studies. Therefore, there is a need for a detailed optical study with an emphasis on flow-field visualization to help understand isobaric combustion involving multiple injectors. Particularly, flow measurement in CI engines is critical to understand the in-cylinder air-fuel mixing process [22], and hence improving engine efficiency and reducing soot emissions.

There are numerous techniques used in literature to get the quantitative description of the flow velocity in the combustion engines ranging from point measurement such as hot wire anemometry [23], laser doppler velocimetry (LDV) [24] to 2D flow-field measurement like particle image velocimetry (PIV) [22,25]. In contrast to this complex PIV technique, high-speed soot luminosity images have been used to get the details of the flow-field information in combustion engine 
experiments using a simple technique called flame image velocimetry (FIV) [26-32]. In FIV, a contrast in soot signal resulting from the change in flame luminosity structure is used as a tracking source and then the displacement vectors are determined based on the standard cross-correlation algorithm.

In the present work, we use FIV measurements to better understand the in-flame flow-field details of isobaric combustion using multiple injectors i.e. one centrally mounted (C) on the cylinder head and two side-injectors $(\mathrm{S})$, slant-mounted on cylinder head protruding their nozzle tip near piston-bowl. The experiments were conducted in an optically accessible single-cylinder heavy-duty diesel engine. Bottomview high-speed soot luminosity imaging has been carried out in three different configurations i.e. $(\mathrm{C}+\mathrm{S}),(\mathrm{S}+\mathrm{C})$, and $(\mathrm{S}+\mathrm{S})$ for understanding the multiple injectors configuration of isobaric combustion, where the PCP was kept fixed at 50 bar. The results from the FIV analysis provide insight into the effect of flow structures on the performance and emission parameters of isobaric combustion.

\section{Experimental method}

\section{Optical engine setup and operating conditions}

The experiments were conducted in an optically accessible singlecylinder heavy-duty diesel engine. The schematic of the optical engine for the isobaric combustion using multiple injectors is shown in Figure 1. The conventional 12.8-liter, 6-cylinder Volvo D13C500 diesel engine was modified by enabling only one of the cylinders and deactivating the rest of the cylinders. Further, the modifications include the installation of a Bowditch extended piston, which was equipped with an $\omega$-shaped optical piston, along with a liner and windows holder; thus, creating an optical combustion chamber. The optical engine was equipped with three quartz windows providing a side view access, along with a $45^{\circ} \mathrm{UV}$-mirror mounted below the extended piston providing bottom view access of the combustion chamber.

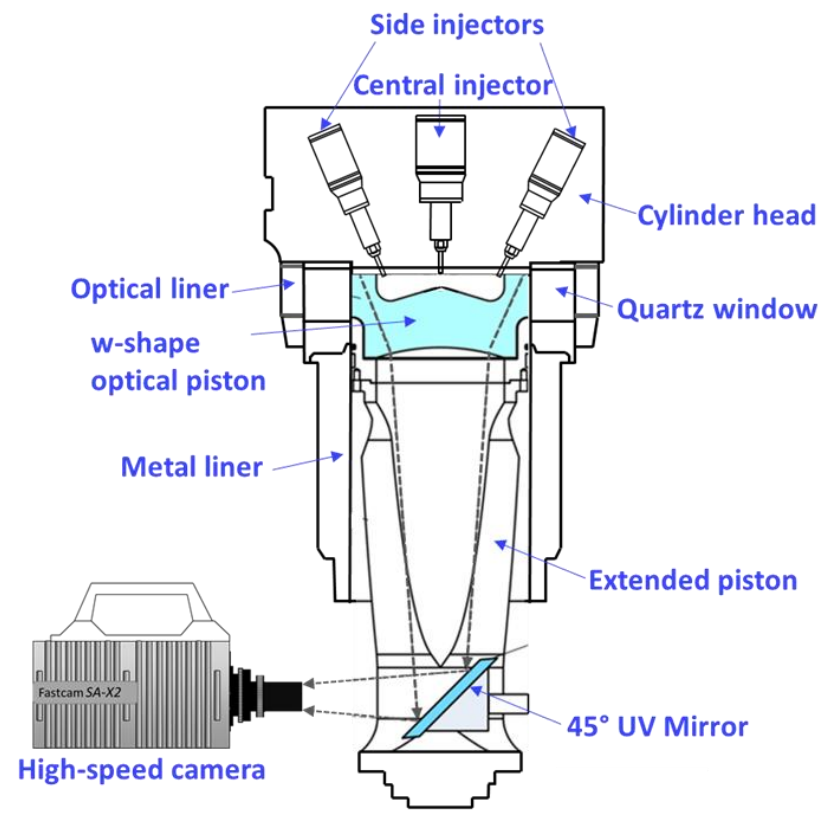

Figure 1. Schematic of the optical engine and line-of-sight high-speed soot luminosity bottom view imaging system.

Three injectors were employed on the cylinder head i.e. one centrally mounted (C) on the cylinder head and two side-injectors (S), slantmounted on cylinder head protruding their nozzle tip near piston-bowl Page 2 of 11 to achieve the isobaric combustion. The side-injectors were inclined at $9^{\circ}$ to the vertical plane of the cylinder head. The central injector consists of 6 nozzle holes while each side injector has 3 nozzle holes configuration; thereby flow rate of each side injector is approximately half the flow rate of the central injector. The exact location of the central and side injectors mounted on the cylinder head from the bottom and top view perspective along with the liquid-phase spray imaging from these injectors are depicted in Figure 2.

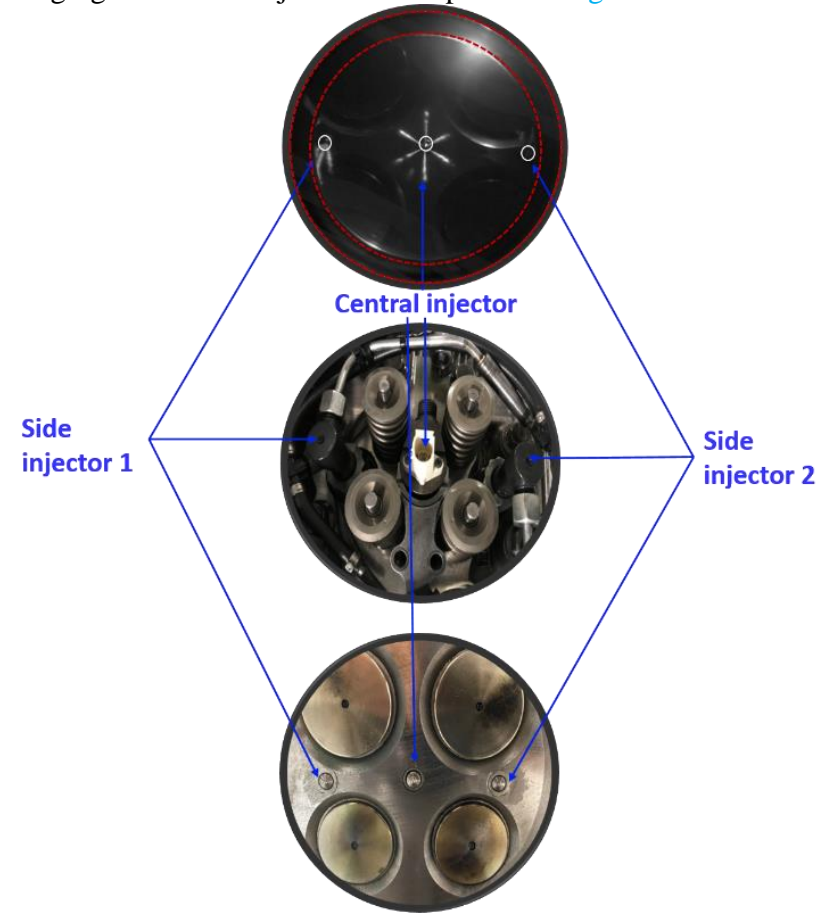

Figure 2. The top picture represents the high-speed imaging of the liquidphase spray using multiple injectors, indicating a central injector with six spray jets and two outer side injectors with three-spray jets. The middle picture and bottom picture show the cylinder head of the Volvo D13C500 diesel engine from the top and bottom view, respectively, indicating the location of all three injectors.

Table 1. Engine parameters and operating conditions.

\begin{tabular}{|l|l|}
\hline Engine speed $[\mathrm{rpm}]$ & 1200 \\
\hline Intake/Exhaust pressure $[\mathrm{bar}]$ & $\sim 1.6 / 1.8$ \\
\hline Intake air temperature $\left[{ }^{\circ} \mathrm{C}\right]$ & $\sim 25$ \\
\hline Coolant temperature $\left[{ }^{\circ} \mathrm{C}\right]$ & $\sim 60$ \\
\hline Oil temperature $\left[{ }^{\circ} \mathrm{C}\right]$ & $\sim 60$ \\
\hline Common-rail pressure $[\mathrm{bar}]$ & 1500 \\
\hline Engine firing mode & Skip-fire \\
\hline Fuel & n-heptane \\
\hline Fuel injection strategy & Multiple \\
\hline Overall air excess ratio $[\lambda]$ & 3 \\
\hline Fuel MEP $[$ bar] & $16 \pm 2$ \\
\hline Total injected fuel mass $[\mathrm{mg} / \mathrm{cycle}]$ & $78 \pm 10$ \\
\hline & $2.05(\mathrm{C}+\mathrm{S})$ \\
\hline & $1.77(\mathrm{~S}+\mathrm{C})$ \\
\hline
\end{tabular}

Table 1 provides the summary of engine parameters and operating conditions. The engine was operated at 1200 revolutions per minute (rpm), which is kept fixed for all the experiments. The intake air temperature was kept at $25^{\circ} \mathrm{C}$ and the intake pressure was boosted to 
1.6 bar to achieve the peak motoring pressure (PMP) of 50 bar after compression. The coolant temperature was maintained at $60{ }^{\circ} \mathrm{C}$, which simulate the warmed-up and thermally stable engine operating condition of the combustion chamber wall temperature. The commonrail pressure was fixed at 1500 bar and experiments were conducted using n-heptane fuel, which is the surrogate fuel of diesel. A skip-fire mode was used, where five cycles were fired followed by five motored cycles to reduce the thermal stress on the optical parts. A total of 50 cycles (fired and motored) were recorded for each experimental condition. The coefficient of variation (CoV) of IMEP was kept below $5 \%$, which represents stable engine operating conditions.

\section{Engine specifications and camera parameters}

The engine specifications and camera parameters used in the present experimental study are listed in Table 2 . The current optical engine with an activated single cylinder has a displacement volume of 2.13 liters with a $131 \mathrm{~mm}$ bore size and $158 \mathrm{~mm}$ stroke. The effective compression ratio, accounting for the blow-by-losses from piston rings of the engine is 11.67. A distributed pump common-rail system (Delphi F2E) was used for the direct injection of fuel through a centrally-mounted injector on the cylinder head and two side injectors slant-mounted on the cylinder head protruding their nozzle tip near the piston-bowl wall. Figure 1 shows the schematic representation of the optical diagnostics setup used in the present study. A Photron SA-X2 fast camera equipped with a $50 \mathrm{~mm}, \mathrm{f} / 5.6$ lens was used to capture the line-of-sight high-speed soot luminosity imaging from the bottom view of the combustion chamber. The frame rate and exposure time of the camera were set to 20,000 frames per second and $2.5 \mu$ s, respectively. This gives the temporal resolution of $0.36{ }^{\circ} \mathrm{CA}$ at an engine speed of $1200 \mathrm{rpm}$. A neutral density (ND2) filter was used to avoid signal saturation and achieve a better signal contrast for FIV analysis.

Table 2. Engine specifications and camera parameters.
\begin{tabular}{|l|l|}
\hline \multicolumn{2}{|c|}{ Engine specifications } \\
\hline Bore/Stroke [mm] & $131 / 158$ \\
\hline Displacement volume [liters] & 2.13 \\
\hline Connecting rod [mm] & 255 \\
\hline Compression ratio & $\sim 11.67$ (effective) \\
\hline Fuel injection system & Delphi F2E common-rail \\
\hline \multirow{2}{*}{ Number of nozzle holes } & 6 (central injector) \\
\cline { 2 - 3 } & 3 (side injectors) \\
\hline Included angle for central injector & 145 degrees \\
\hline $\begin{array}{l}\text { Plume separation angle with respect } \\
\text { to injector axis for side injectors }\end{array}$ & $\begin{array}{l}66.4 \text { degrees, 68.6 degrees, and } 72 \\
\text { degrees }\end{array}$ \\
\hline Nominal hole diameter [ $\mu \mathrm{m}]$ & $\sim 240$ \\
\hline & Camera parameters \\
\hline Frame rate [fps] & 20,000 \\
\hline Shutter speed [ $\mu$ s] & 2.5 \\
\hline Filter & Neutral Density (ND) \\
\hline Aperture & f/5.6 \\
\hline Lens focal length [mm] & 50 \\
\hline
\end{tabular}

\section{Multiple injection Strategy for isobaric combustion}

Table 3 provides the summary of the multiple injection strategies showing the three different configurations i.e. $(\mathrm{C}+\mathrm{S}),(\mathrm{S}+\mathrm{C})$, and $(\mathrm{S}+\mathrm{S})$ to achieve the isobaric combustion. In all three configurations of

Page 3 of 11 injection strategy used for present experiments, two injection strategy was implemented i.e. one before TDC and other after TDC. The first injection was used to create the premixed charge while the second injection was resulting in combustion and hence controlling the heat release rate (HRR). The injections from both the side injectors were injected at the same crank angle degree (CAD) along with the same injection duration. The injection timing and duration were accordingly adjusted to achieve the isobaric combustion keeping the constant PCP of 50 bar and constant overall excess air ratio at 3 for all the three different configurations shown in Table 3.

Table 3. Injection strategy showing the injection timing and duration for isobaric combustion.

\begin{tabular}{|c|c|c|}
\hline $\begin{array}{l}\text { Injection Strategy } \\
\text { for Isobaric } \\
\text { Combustion }\end{array}$ & $\begin{array}{c}\text { Injection timing } \\
{\left[{ }^{\circ} \mathrm{CA} \text { aTDC }\right]}\end{array}$ & $\begin{array}{c}\text { Injection duration } \\
{[\mu \mathrm{s}]}\end{array}$ \\
\hline $\begin{array}{l}\text { Central + } \\
(\text { Side1 + Side 2) }\end{array}$ & $\begin{array}{l}-2.5 \\
(5,5)\end{array}$ & $\begin{array}{l}400, \\
(550,550)\end{array}$ \\
\hline $\begin{array}{l}(\text { Side } 1+\text { Side } 2)+ \\
\text { Central }\end{array}$ & $\begin{array}{l}(-0.5,-0.5) \\
9\end{array}$ & $\begin{array}{l}(400,400), \\
620\end{array}$ \\
\hline $\begin{array}{l}(\text { Side } 1+\text { Side } 2)+ \\
(\text { Side } 1+\text { Side } 2)\end{array}$ & $\begin{array}{l}(-2,-2), \\
(4,4)\end{array}$ & $\begin{array}{l}(340,340), \\
(470,470)\end{array}$ \\
\hline
\end{tabular}

\section{Flame Image Velocimetry (FIV)}

The high-speed soot luminosity images were utilized to get the incylinder flow field information by carrying out the FIV analysis using PIVLab [33], a MATLAB-based open-source code. A detailed description of the workflow for the digital particle image velocimetry technique and the features available in PIVLab are provided in a previous study [33].

The major steps involved in the FIV procedure for obtaining the velocity field distribution from the soot luminosity images are shown in Figure 3. In the first step, raw soot luminosity images captured using a high-speed camera were imported into PIVLab, which were then converted into sequential frame images. Each frame image consists of two consecutive images, separated by the time step equal to the inverse of the frame rate used in capturing high-speed soot luminosity images. In the second step, these input images were pre-processed using contrast limited adaptive histogram equalization (CLAHE) filter algorithm. CLAHE divides the input image into a small processing window and enhances the signal contrast locally through histogram equalization such that more distinct flame structures are revealed while retaining the overall signal distribution as of the original image. In the present study, the optimized CLAHE window size of $16 \times 16$ pixels was used, as in previous diesel flame FIV analysis [32]. Other steps involved in pre-processing are masking the undesired area and selecting the region of interest.

The third step is the image evaluation step, where the pre-processed images were evaluated using a cross-correlation algorithm to estimate the pixel displacement within the image frame. Each image frame was processed for small sub-images (interrogation areas), where an image pair were cross-correlated to determine the most probable displacement in the interrogation areas. A multi-pass discrete Fourier transform (DFT) approach with default $50 \%$ window overlap was implemented along with a Gaussian $2 \times 3$ point estimator to find the peak for determining the most probable displacement. The DFT-based method computes the cross-correlation matrix in the frequency domain [34], which is computationally efficient. The use of a multi-pass interrogation window gives the flexibility to refine the interrogation grid with every pass giving the high vector resolution with optimum signal to noise ratio [35]. The selection of the final interrogation window size of the multi-pass DFT-based algorithm is one of the critical parameters of FIV analysis in determining the accuracy and optimum vector resolution. The criteria for choosing this final 
interrogation window was decided by the quarter rule [36], which states that the interrogation window size should be larger than 4 times the largest pixel displacement. The largest pixel displacement was first determined with a relatively larger interrogation window size (say $36 \times 36$ pixels) and thus obtained maximum pixel displacement was used to get the optimized final interrogation window based on the quarter rule, which was set to $20 \times 20$ pixels in the present study. This divides the input image of $470 \times 470$ pixels into 47 small sub-images and hence computes the pixel displacement.

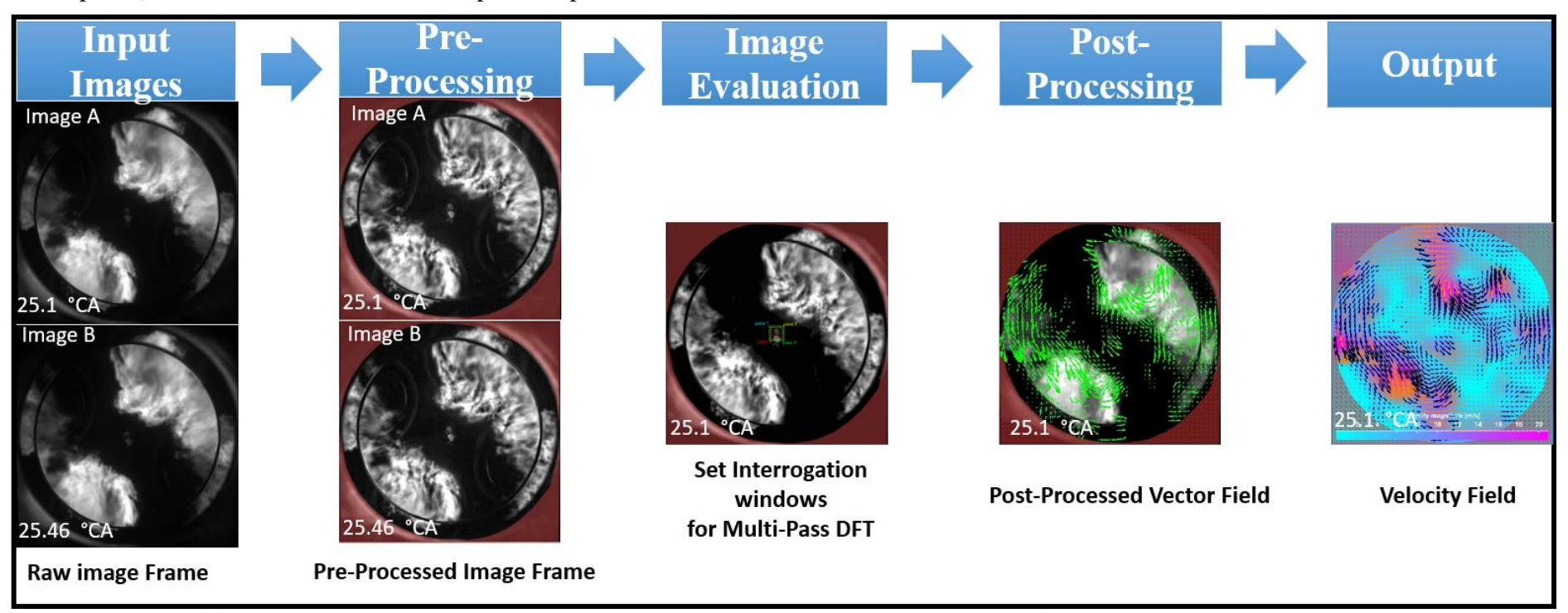

Figure 3. Overview of flame image velocimetry (FIV) analysis procedure using PIVLab, shown for the $\mathrm{C}+\mathrm{S}$ configuration of isobaric combustion.

The other interrogation windows for the third, second, and first pass set to $24 \times 24$ pixels, $28 \times 28$ pixels, and $32 \times 32$ pixels, respectively which were set in the gradually increasing order from the final interrogation window size. The fourth step of FIV analyses is postprocessing, which involves the removal of the erroneous vectors, followed by replacing them with interpolated vectors. In the present study, the velocity limit and median filter were applied to the evaluated vectors to remove any false estimation of vectors. The velocity limit set in the present analysis was 5 pixels/ frame and the median filter threshold was set to default 3 pixels. This velocity limit criteria is also very important in deciding the accuracy and optimum resolution of vectors, as this is linked to the selection of the final interrogation window size of the image evaluation step through the quarter rule. An overlay of vectors obtained from the FIV analysis on soot luminosity images was represented in the post-processed vector field; which was found to be well mapped. Finally, in the last step, any derived quantities of interest could be plotted. In this study, the results from the vector field are further post-processed to get the velocity map of the entire flow field in the combustion chamber. The two-dimensional spline interpolation technique was used to populate the interpolated vectors (orange in color) in the velocity field.

\section{Results and Discussion}

\section{In-cylinder pressure, heat release rate, and gross indicated efficiency}

Figure 4 shows the cycle averaged in-cylinder pressure and heat release rate traces for isobaric combustion using multiple injectors. Out of 5 continuous firing cycles (and 25 total firing cycles) for each combustion configuration, the first firing cycle has been ignored as it did not result in stable combustion. Therefore, the rest of the 20 firing cycles were averaged to obtain the in-cylinder pressure and HRR. All these traces are shown for the three different configurations i.e. $(\mathrm{C}+\mathrm{S})$, $(\mathrm{S}+\mathrm{C})$, and $(\mathrm{S}+\mathrm{S})$ of isobaric combustion, where the PCP is maintained at 50 bar. Results from the pressure traces show that the isobaric combustion is successfully achieved using multiple injectors with different injection strategies. However, some waviness in the pressure traces is observed, which could be probably resolved by increasing the Page 4 of 11 number of injections and would be interesting to investigate further. The heat release analysis was performed based on the first law of thermodynamics while the quadratic assumption of in-cylinder temperature was considered for the estimation of specific heat ratio as calculated in previous studies $[11,12]$. The HRR traces show that the configurations $\mathrm{C}+\mathrm{S}$ and $\mathrm{S}+\mathrm{S}$, result in a longer burn duration (44.2 and $44.5^{\circ} \mathrm{CA}$ aTDC, respectively), and lower gross indicated efficiency (39.4 and $39.9 \%$, respectively) than the $\mathrm{S}+\mathrm{C}$ case $\left(23.1^{\circ} \mathrm{CA}\right.$ aTDC burn duration and $44.3 \%$ gross indicated efficiency) as highlighted in Table 4. The in-cylinder pressure and heat release rate for baseline cases (using only central injectors) for CDC and isobaric combustion are shown in Appendix A.

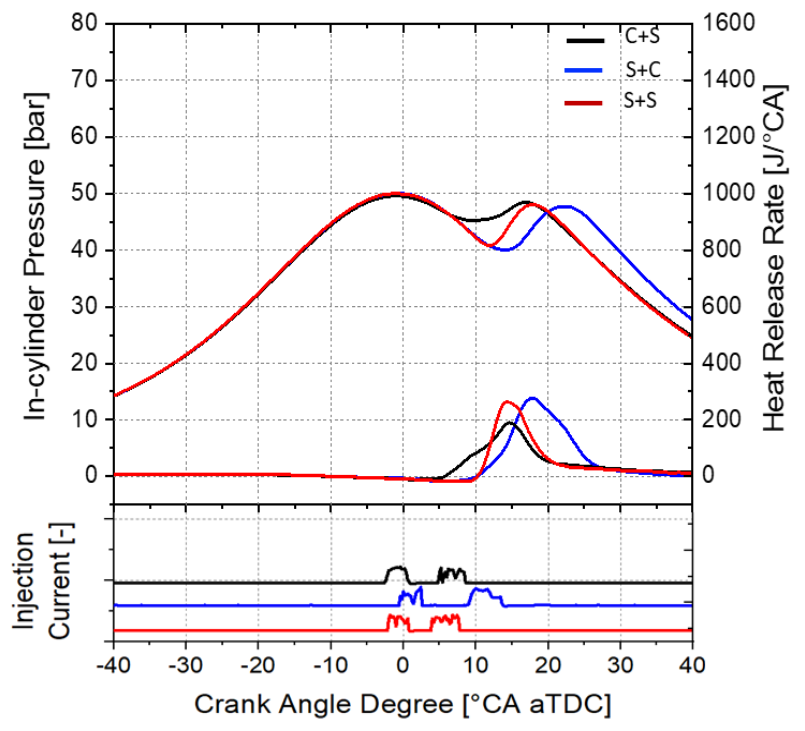

\begin{tabular}{|c|c|c|c|}
\hline $\begin{array}{c}\text { Injection } \\
\text { Strategy for } \\
\text { Isobaric } \\
\text { Combustion }\end{array}$ & $\begin{array}{c}\mathrm{CA50} \\
{\left[{ }^{\circ} \mathrm{CA} \text { aTDC }\right]}\end{array}$ & $\begin{array}{c}\text { Gross } \\
{\left[{ }^{\circ} \mathrm{CA} \text { 10-90 }\right.}\end{array}$ & $\begin{array}{c}\text { ITDC] }] \\
\text { Indiacted } \\
\text { Efficiency } \\
(\boldsymbol{\%})\end{array}$ \\
\hline $\mathrm{C}+\mathrm{S}$ & 19.6 & 44.2 & 39.4 \\
\hline $\mathrm{S}+\mathrm{C}$ & 20.5 & 23.1 & 44.3 \\
\hline $\mathrm{S}+\mathrm{S}$ & 19.5 & 44.5 & 39.9 \\
\hline
\end{tabular}


Table 4. Combustion phasing (CA50), Burn duration (CA10-90), and Gross indicated efficiency for the $(\mathrm{C}+\mathrm{S}),(\mathrm{S}+\mathrm{C})$, and $(\mathrm{S}+\mathrm{S})$ configuration of isobaric combustion.

Peak HRR CAD
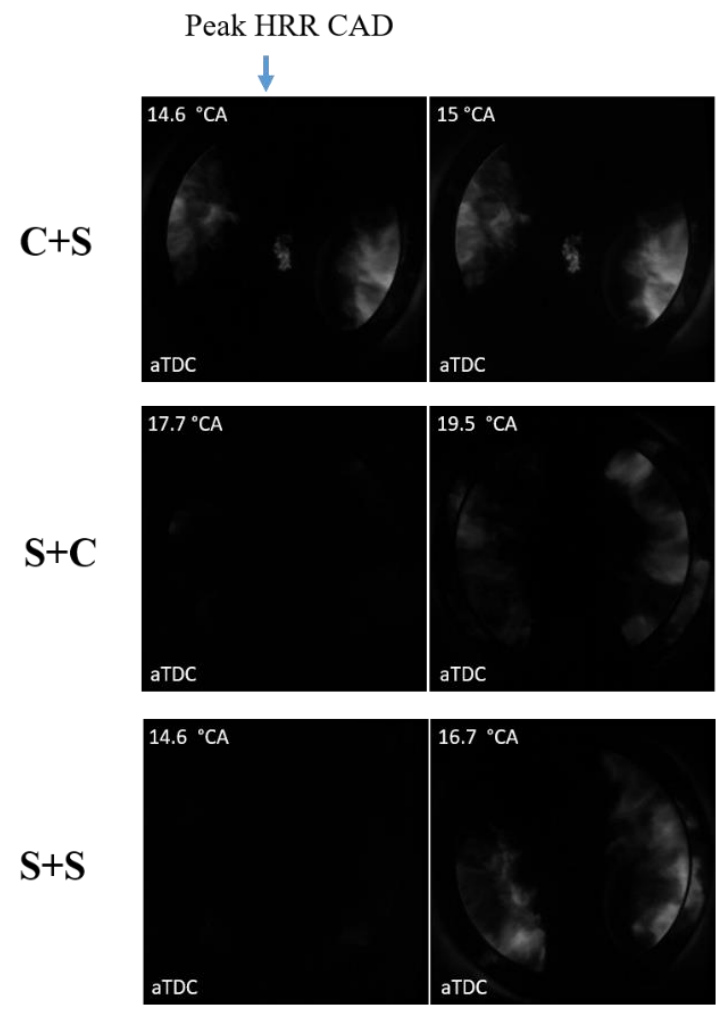

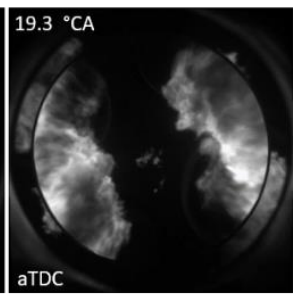

Peak luminous

intensity $\mathrm{CAD}$
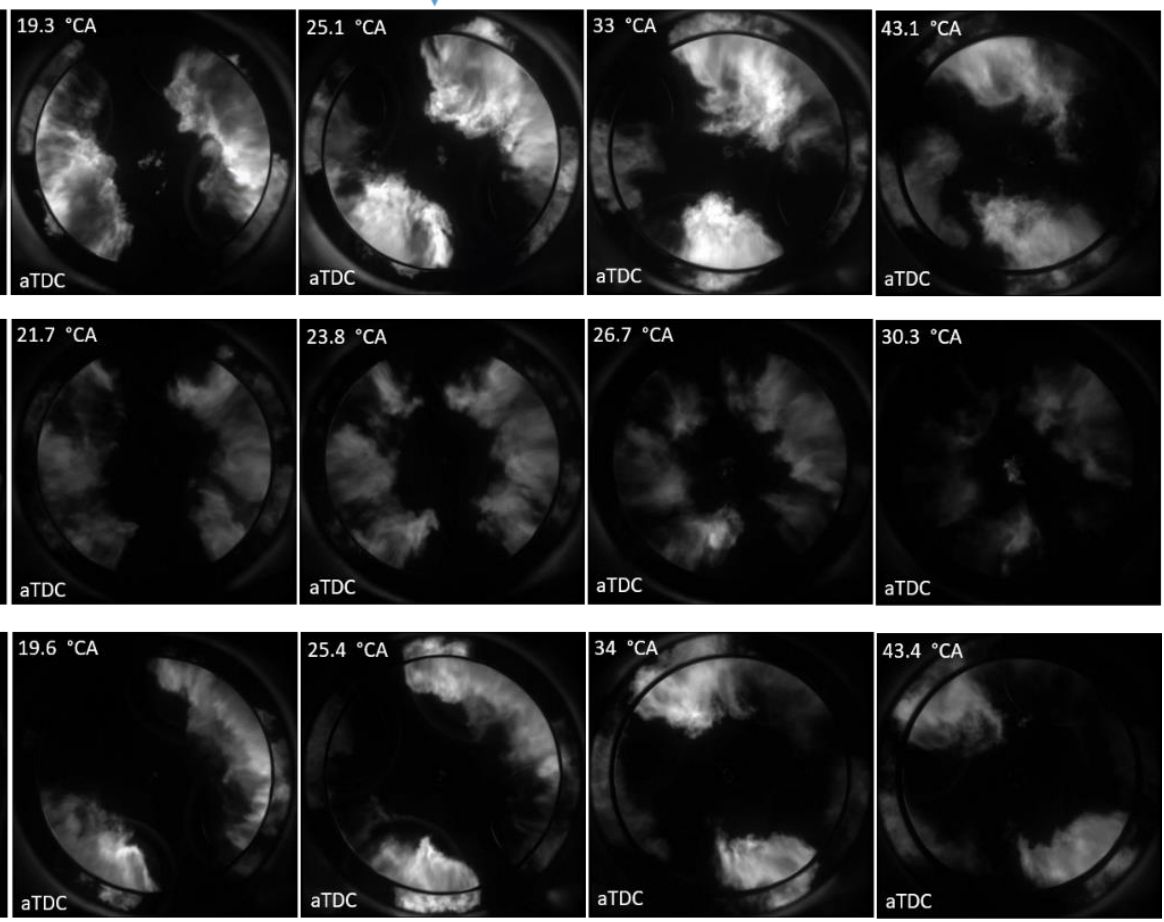

Figure 5. High-speed soot luminosity imaging for the $(\mathrm{C}+\mathrm{S}),(\mathrm{S}+\mathrm{C})$, and $(\mathrm{S}+\mathrm{S})$ configuration of isobaric combustion.

\section{High-speed soot luminosity images}

The bottom view distortion corrected high-speed soot luminosity images for the three different configurations of isobaric combustion i.e. $\mathrm{C}+\mathrm{S}, \mathrm{S}+\mathrm{C}$ and $\mathrm{S}+\mathrm{S}$ are shown in the first, second, and third row of Figure 5, respectively. A detailed procedure about the bottom view distortion correction method applied to a standard $\omega$-shape piston in the same engine is explained in the previous study [37]. The selected images shown in Figure 5 are from the 25th fired cycle of skip-firing mode, which is a closer representative cycle to the averaged pressure traces of isobaric combustion. Soot luminosity images in the first column correspond to the CAD where the HRR peaks. The highest luminous intensity for all cases is showcased in images in the fourth column.

From the high-speed soot luminosity images, $\mathrm{C}+\mathrm{S}$ and $\mathrm{S}+\mathrm{S}$ cases showed a swirl motion around the bowl-wall. This swirl motion is attributed to injections from the side injectors as the sprays are tangential to the bowl-wall, given the engine has close to zero swirl motion. An example of the liquid-phase spray imaging employing all three injectors under non-reacting conditions is shown in Figure 2. The generation of swirl due to side injectors is consistent with a previous study [18].

Page 5 of 11
Although the first injection event is not captured during the high-speed soot luminosity imaging, it has a strong impact on creating localized fuel-rich mixing zones. For example, the $\mathrm{C}+\mathrm{S}$ configuration of isobaric combustion shows a larger soot luminosity area as compared to the $\mathrm{S}+\mathrm{S}$ configuration, which is evident from Figure 5. Further, from Figure 5, the $\mathrm{S}+\mathrm{C}$ configuration shows the lowest luminous intensity signals among other configurations; which is confirmed from Figure 6 , highlighting the quantitative perspective of observed phenomena seen from high-speed luminosity images. The rationale for the lowest soot luminous intensity in the $\mathrm{S}+\mathrm{C}$ case could be attributed to the second injection from the central injector which is more distributed and injecting into the already formed premixed charge region, created from the first injection using both side injectors. This might have resulted in better soot oxidation and hence shows the lowest luminosity intensity signal. 


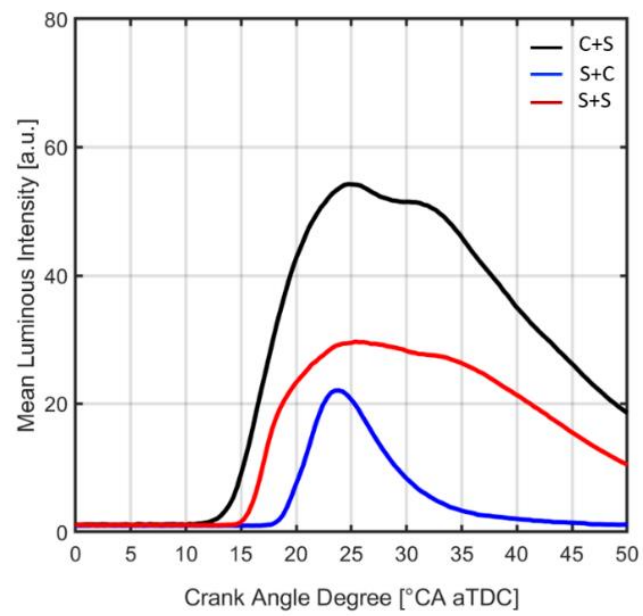

Figure 6. Mean luminous intensity plot as a function of crank angle degree for the $(\mathrm{C}+\mathrm{S}),(\mathrm{S}+\mathrm{C})$, and $(\mathrm{S}+\mathrm{S})$ configuration of isobaric combustion.

FIV analysis using high-speed soot luminosity images

Page 6 of 11 


\section{$\mathrm{C}+\mathrm{S}$ Configuration}

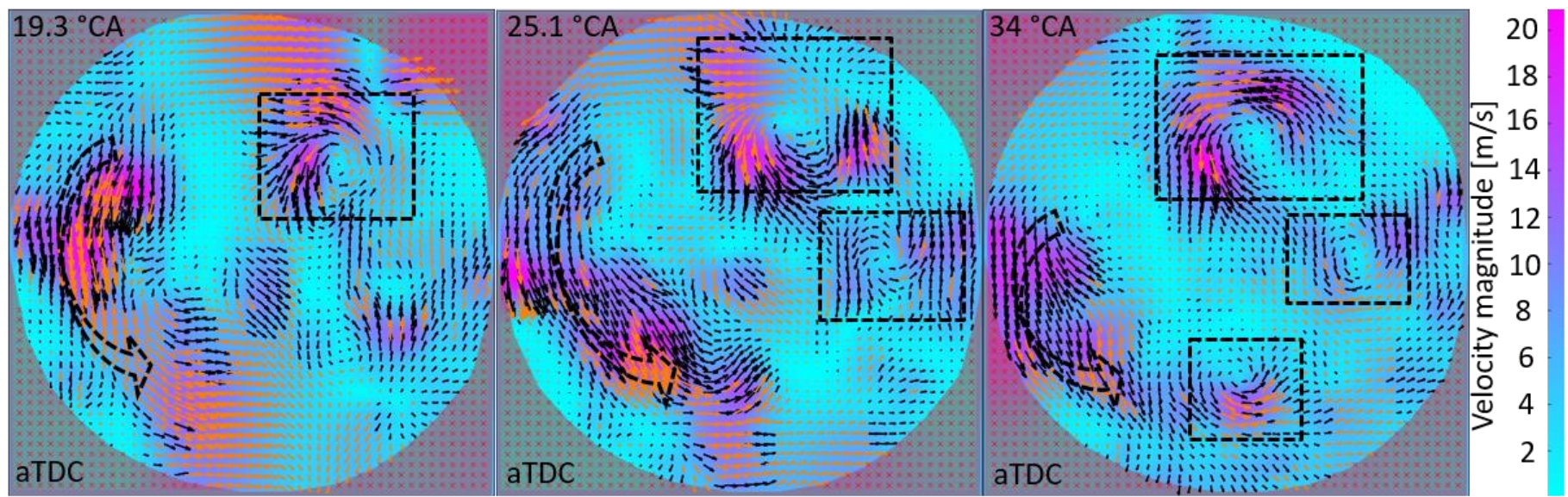

\section{S+C Configuration}

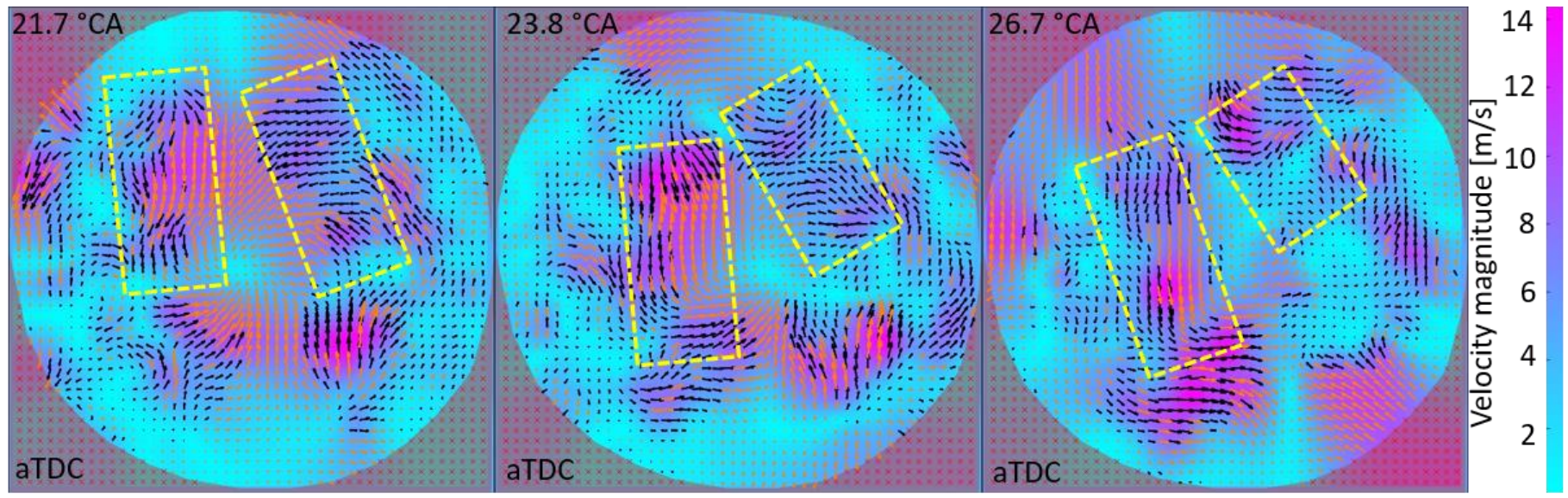

\section{$\mathbf{S}+\mathbf{S}$ Configuration}

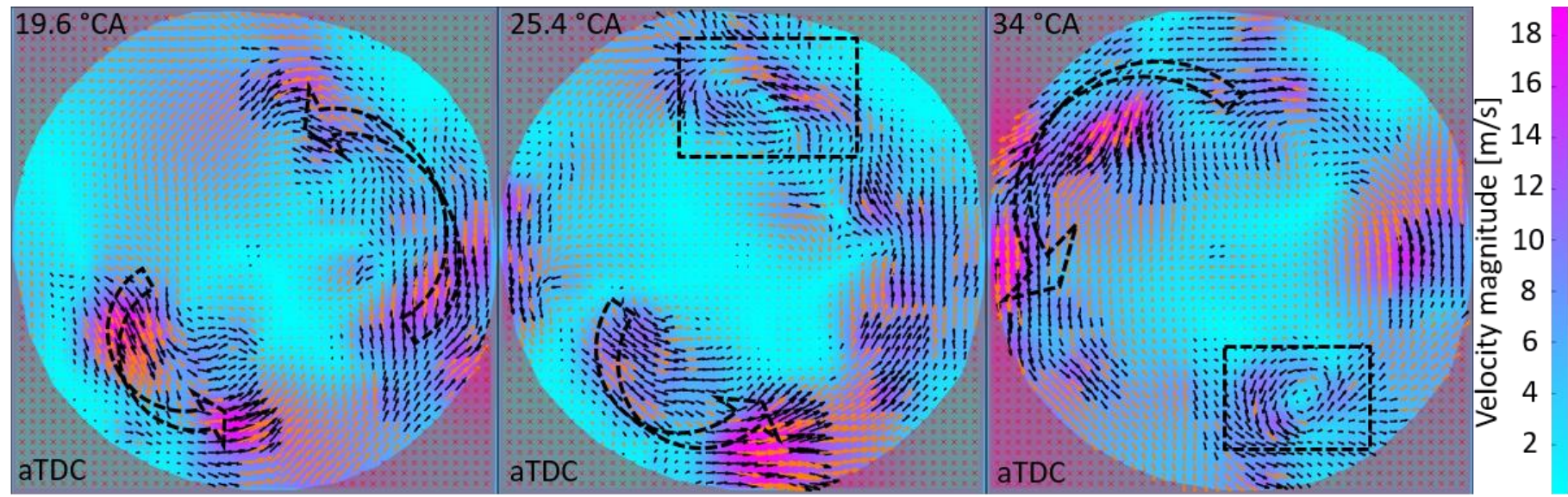

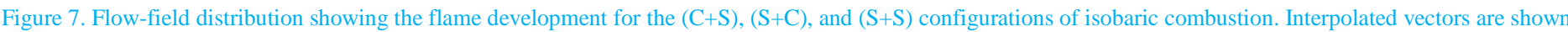
in orange color in the flow-field. 
Figure 7 illustrates the FIV results showing the velocity field for $\mathrm{C}+\mathrm{S}$ (top row), $\mathrm{S}+\mathrm{C}$ (middle row), and $\mathrm{S}+\mathrm{S}$ (bottom row) configurations of isobaric combustion. As FIV is using the contrast of soot signals in determining the velocity vectors, the analysis requires images where the strong soot luminosity signals are present. Therefore, in the present study, soot luminosity images near the peak intensity CAD were selected for the FIV processing (see Figure 5).

The FIV-derived flow vectors represented in Figure 7 show the spatial and temporal evolution of sooting flames along with the flow-field differences in different configurations of isobaric combustion. The velocity field provides much more detailed information revealing distinct flow patterns from the visual inspection of high-speed soot luminosity images (Figure 5). In particular, the analysis helps to explain the higher gross indicated efficiency observed for the $\mathrm{S}+\mathrm{C}$ case compared to the $\mathrm{C}+\mathrm{S}$ and $\mathrm{S}+\mathrm{S}$ configurations.

In the $\mathrm{C}+\mathrm{S}$ configuration of isobaric combustion, the strong flame wall interaction leads to a counter-clockwise swirling motion (highlighted in black dashed arrows) as well as distinct vortex structures (shown in black dashed boxes) around the bowl-wall for CAD ranging from 19.3 to $34{ }^{\circ} \mathrm{CA}$ aTDC. Additional vortex structures around the bowl-wall become evident as combustion progresses temporally from $19.3{ }^{\circ} \mathrm{CA}$ aTDC towards the later CAD.

The $\mathrm{S}+\mathrm{S}$ configuration also presents a counter-clockwise swirling motion (highlighted in black dashed arrows) and vortex structures (shown in black dashed boxes) near the bowl-wall as already observed for the $\mathrm{C}+\mathrm{S}$ configuration. However, using the side injectors for both fuel injections leads to fewer vortex structures than in the $\mathrm{C}+\mathrm{S}$ configuration. The flame-wall interaction effects [31] in $\mathbf{S}+\mathrm{S}$ configuration are clearly evident at $19.6{ }^{\circ} \mathrm{CA}$ aTDC showing the strong flow vectors traveling along the bowl-wall in both up-swirl and downswirl sides of flame.

In contrast to these two configurations, flow-field distribution in the $\mathrm{S}+\mathrm{C}$ configuration of isobaric combustion looks more chaotic and vortex structures are less prominent close to the bowl-wall. Rotating structures are instead present in the region where the flames merge (shown in yellow dashed boxes), close to the center of the combustion chamber as seen from the CAD ranging from 21.7 to $26.7^{\circ} \mathrm{CA}$ aTDC. This could be probably attributed to the strong flame-flame interactions [32], which are evident in Figure 7 (S+C Configuration) showing the flow vectors from the two adjacent flames are interacting with each other and thus, resulting in a more distributed combustion mode. The distributed combustion comes to the benefit of $\mathrm{S}+\mathrm{C}$ configuration, given the better utilization of the available in-cylinder air. Further, due to the strong flame-flame interactions in $\mathrm{S}+\mathrm{C}$ configurations, the jet momentum decreased around the interaction zones characterized by lower velocity magnitude compared to the $\mathrm{C}+\mathrm{S}$ and $\mathrm{S}+\mathrm{S}$ configurations.

To summarize, from the FIV analysis, the large vortex structures near the cylinder walls for $\mathrm{C}+\mathrm{S}$ and $\mathrm{S}+\mathrm{S}$ configurations were observed, while for the $\mathrm{S}+\mathrm{C}$ configuration, vortex structures are less prominent close to the bowl-wall. Further, in $\mathrm{C}+\mathrm{S}$ and $\mathrm{S}+\mathrm{S}$ configurations, the poor utilization of the combustion chamber volume and the presence of vortex structure limited to the bowl-wall, resulted in reduced mixing and hence the higher levels of soot intensity signals. The presence of strong flame-flame interactions in $\mathrm{S}+\mathrm{C}$ configurations results in vortex structures in a region where flame merges, close to the center of the combustion chamber. This helps in more distributed combustion leading to higher gross indicated efficiency as the heat release rate occurs for a shorter duration [38] (seen from Table 4). On the other hand, the distributed combustion in the $\mathrm{S}+\mathrm{C}$ configuration enhances the mixing, resulting in lower soot emissions.
From the results obtained and discussed above, it is clear that the $\mathrm{S}+\mathrm{C}$ configuration is the best in terms of engine performance and soot reduction among the tested configurations of the isobaric combustion using multiple injectors. These observed trends in engine efficiency and soot emissions are complemented and hence, successfully explained using flow-field details obtained from the FIV analysis.

\section{Summary/Conclusions}

Optical diagnostics consisting of high-speed soot luminosity imaging and FIV analysis were carried out in a heavy-duty single-cylinder optical engine to understand the in-cylinder flow-field of isobaric combustion using multiple injectors. Three different configurations of isobaric combustion i.e. $\mathrm{C}+\mathrm{S}, \mathrm{S}+\mathrm{C}$, and $\mathrm{S}+\mathrm{S}$ have been successfully achieved and the comparative study on flow field details has been discussed. Major findings of this study based on the present experimental configuration at PCP of 50 bar and an engine speed of $1200 \mathrm{rpm}$ are listed as follows:

- $\mathrm{S}+\mathrm{C}$ configuration of isobaric combustion shows the highest gross indicated efficiency and lowest mean luminous intensity - an indicator of soot emission compared to other tested configurations.

- In the $\mathrm{C}+\mathrm{S}$ and $\mathrm{S}+\mathrm{S}$ configuration of isobaric combustion, the second-injection induced by side injectors creates the swirling motion and the vortex structures near the bowl-wall, which could be a result of strong flame-wall interactions. In the $\mathrm{S}+\mathrm{C}$ configuration, where the second injection is from the central injection, the vortex structures are found to be less prominent close to the bowl-wall. However, the presence of strong flame-flame interactions results in vortex structures close to the center of the combustion chamber, where flame merges.

- The large vortex structure close to the bowl-wall for $\mathrm{C}+\mathrm{S}$ and $\mathrm{S}+\mathrm{S}$ configurations leads to reduced mixing and hence higher soot-formation, compared to the $\mathrm{C}+\mathrm{S}$ configuration of isobaric combustion. It is important to highlight that different engine load/speed conditions can impact the optimized configuration of multiple injectors.

\section{Future work}

The experimental results show that one of the jets from the side injectors is hitting the squish region, and the other two are tangent to the bowl-wall. Different orientations of the side injectors that avoid the vorticial structures near the bowl-wall, can lead to improved gross indicated efficiency for all configurations, which would be of interest in future investigations.

\section{References}

1. Dec, J.E., "A Conceptual Model of DI Diesel Combustion Based on Laser-Sheet Imaging," SAE Trans. 106(3):13191348, 1997.

2. https://dieselnet.com/standards/.

3. Christensen, M., Johansson, B., and Einewall, P., "Homogeneous Charge Compression Ignition (HCCI) Using Isooctane, Ethanol and Natural Gas - A Comparison with Spark Ignition Operation," SAE Technical Paper 972874 , 
Dec, J.E., "Advanced compression-ignition engines Understanding the in-cylinder processes," Proc. Combust. Inst. 32 II(2):2727-2742, 2009, doi:10.1016/j.proci.2008.08.008.

5.

Kokjohn, S., Reitz, R.D., Splitter, D., and Musculus, M., "Investigation of Fuel Reactivity Stratification for Controlling PCI Heat-Release Rates Using High-Speed Chemiluminescence Imaging and Fuel Tracer Fluorescence," SAE Int. J. Engines 5(2):248-269, 2012, doi:10.4271/2012-01-0375.

6. Kalghatgi, G.T., Hildingsson, L., Harrison, A.J., and Johansson, B., "Autoignition quality of gasoline fuels in partially premixed combustion in diesel engines," Proc. Combust. Inst. 33(2):3015-3021, 2011, doi:10.1016/j.proci.2010.07.007.

7. Raman, V., Tang, Q., An, Y., Shi, H., Sharma, P., Magnotti, G., Chang, J., and Johansson, B., "Impact of spray-wall interaction on the in-cylinder spatial unburned hydrocarbon distribution of a gasoline partially premixed combustion engine," Combust. Flame 215:157-168, 2020, doi:10.1016/j.combustflame.2020.01.033.

8. Goyal, H. and Kook, S., "Ignition process of gasoline compression ignition (GCI) combustion in a small-bore optical engine," Fuel 256(August):115844, 2019, doi:10.1016/j.fuel.2019.115844.

9. Bendu, H. and Murugan, S., "Homogeneous charge compression ignition (HCCI) combustion: Mixture preparation and control strategies in diesel engines," Renew. Sustain. Energy Rev. 38:732-746, 2014, doi:10.1016/j.rser.2014.07.019.

10. Alramadan, A.S., Houidi, M. Ben, Nyrenstedt, G., and Johansson, B., "Fuel Flexibility Study of a Compression Ignition Engine at High Loads," SAE Technical Paper 201901-2193, 2019, doi:10.4271/2019-01-2193.

11. Babayev, R., Houidi, M. Ben, Andersson, A., and Johansson, B., "Isobaric Combustion: A Potential Path to High Efficiency, in Combination with the Double Compression Expansion Engine (DCEE) Concept," $S A E$ Technical Paper 2019-01-0085, 2019, doi:10.4271/2019-010085 .

12. Dyuisenakhmetov, A., Goyal, H., Houidi, M. Ben, Babayev, R., Badra, J., and Johansson, B., "Isobaric Combustion at a Low Compression Ratio," SAE Technical Paper 2020-010797, 2020, doi:10.4271/2020-01-0797.

13. Okamoto, T. and Uchida, N., "New Concept for Overcoming the Trade-Off between Thermal Efficiency, Each Loss and Exhaust Emissions in a Heavy Duty Diesel Engine," SAE Int. J. Engines 9(2), 2016, doi:10.4271/201601-0729.

14. Goyal, H., Dyuisenakhmetov, A., Houidi, M. Ben, Johansson, B., Badra, J., Cenker, E., and Chang, J., "The Effect of Engine Speed, Exhaust Gas Recirculation, and Compression Ratio on Isobaric Combustion," SAE Int. J.
15. Lam, N., Tuner, M., Tunestal, P., Andersson, A., Lundgren, S., and Johansson, B., "Double Compression Expansion Engine Concepts: A Path to High Efficiency," SAE Int. J. Engines 8(4):1562-1578, 2015, doi:10.4271/2015-01-1260.

16. Lam, N., Andersson, A., and Tunestal, P., "Double Compression Expansion Engine Concepts: Efficiency Analysis over a Load Range," SAE Technical Paper 201801-0886, 2018, doi:10.4271/2018-01-0886.

17. Goyal, H., Nyrenstedt, G., Moreno Cabezas, K., Panthi, N. et al., "A Simulation Study to Understand the Efficiency Analysis of Multiple Injectors for the Double Compression Expansion Engine ( DCEE ) Concept," SAE Technical Paper 2021-01-0444, 2021, doi:10.4271/2021-01-0444.

18. Uchida, N. and Watanabe, H., "A new concept of actively controlled rate of diesel combustion (ACCORDIC): Part II-simultaneous improvements in brake thermal efficiency and heat loss with modified nozzles," Int. J. Engine Res. 20(1):34-45, 2019, doi:10.1177/1468087418820472.

19. Nyrenstedt, G., Watanabe, K., Enya, K., Shi, H., Uchida, N., and Johansson, B., "Thermal Efficiency Comparison of Different Injector Constellations in a CI Engine," $S A E$ Technical Paper 2020-01-0172, 2019, doi:10.4271/2019-240172.

20. Nyrenstedt, G., Ramadan, A. Al, Tang, Q., Badra, J., Cenker, E., Houidi, M. Ben, and Johansson, B., "Isobaric Combustion for High Efficiency in an Optical Diesel Engine," SAE Technical Paper 2020-01-0301, 2020, doi:10.4271/2020-01-0301.

21. Ramadan, A.S. Al, Nyrenstedt, G., Houidi, M. Ben, and Johansson, B., "Optical Diagnostics of Isooctane and nHeptane Isobaric Combustion," SAE Technical Paper 202001-1126, 2020, doi:10.4271/2020-01-1126.

22. Miles, P.C., Collin, R., Hildingsson, L., Hultqvist, A., and Andersson, Ö., "Combined measurements of flow structure, partially oxidized fuel, and soot in a high-speed, directinjection diesel engine," Proc. Combust. Inst. 31 II(x):29632970, 2007, doi:10.1016/j.proci.2006.07.231.

23. Takamoto, Y. and Gyakushi, N., "Fundamental Characteristics of Squish Flow in D. I. Diesel Engine," JSME Int. J. 30(268):1615-1621, 1987.

24. Cole, J.B. and Swords, M.D., "Laser Doppler anemometry measurements in an engine," Appl Opt 18(10):1539-1545, 1979.

25. Ghandhi, J.B., Herold, R.E., Shakal, J.S., and Strand, T.E., "Time resolved particle image velocimetry measurements in an internal combustion engine," SAE Technical Paper 2005 01-3868, 2005, doi:10.4271/2005-01-3868.

26. Zha, K., Busch, S., Warey, A., Peterson, R.C., and Kurtz, E., "A Study of Piston Geometry Effects on Late-Stage Combustion in a Light-Duty Optical Diesel Engine Using Combustion Image Velocimetry," SAE Int. J. Engines 11(6):783-804, 2018, doi:10.4271/2018-01-0230. 
Dembinski, H. and Angstrom, H.E., "Swirl and injection pressure effect on post-oxidation flow pattern evaluated with combustion image velocimetry, CIV, and CFD simulation," SAE Technical Paper 2013-01-2577, 2013, doi:10.4271/2013-01-2577.

28. Dembinski, H.W.R. and Angstrom, H.E., "Optical study of swirl during combustion in a CI engine with different injection pressures and swirl ratios compared with calculations," SAE Technical Paper 2012-01-0682, 2012, doi:10.4271/2012-01-0682.

29. Zhao, M. and Kaiser, S., "Optical Diagnostics for Knock in Compression-Ignition Engines via High-Speed Imaging," SAE Int. J. Engines 11(6):903-918, 2018, doi:10.4271/201801-0631.

30. Shioji, M., Kimoto, T., Okamoto, M., and Makoto, I., "An Analysis of Diesel Flame by Picture Processing," JSME Int. J. 32(3):434-442, 1989.

31. Yang, J., Rao, L., Zhang, Y., Silva, C. de, and Kook, S., "Flame image velocimetry analysis of reacting jet flow fields with a variation of injection pressure in a small-bore diesel engine," Int. J. Engine Res., 2020, doi:10.1177/1468087420960616.

32. Rao, L. and Kook, S., "Optimisation of image processing parameters for flame image velocimetry (FIV) measurement in a single-cylinder, small-bore optical diesel engine," $S A E$ Int. J. Adv. Curr. Pract. Mobil. 1(3):1311-1324, 2019, doi:10.4271/2019-01-0719.

33. Thielicke, W. and Stamhuis, E.J., "PIVlab - Towards Userfriendly, Affordable and Accurate Digital Particle Image Velocimetry in MATLAB," J. Open Res. Softw. 2, 2014, doi:10.5334/jors.bl.

34. Soria, J., "An investigation of the near wake of a circular cylinder using a video-based digital cross-correlation particle image velocimetry technique," Exp. Therm. Fluid Sci. 12(2):221-233, 1996, doi:10.1016/08941777(95)00086-0.

35. Scarano, F. and Riethmuller, M.L., "Iterative multigrid approach in PIV image processing with discrete window offset," Exp. Fluids 26(6):513-523, 1999, doi:10.1007/s003480050318.

36. Keane, R.D. and Adrian, R.J., "Optimization of particle image velocimeters. I. Double pulsed systems," Meas. Sci. Technol. 1(11):1202-1215, 1990, doi:10.1088/09570233/1/11/013.

37. Tang, Q., An, Y., Raman, V., Shi, H., Sim, J., Chang, J., Magnotti, G., and Johansson, B., "Experimental study on the effects of spray-wall interaction on partially premixed combustion and engine emissions," Energy and Fuels 33(6):5673-5681, 2019, doi:10.1021/acs.energyfuels.9b00602.

38. Shim, E., Park, H., and Bae, C., "Comparisons of Advanced Combustion Technologies (HCCI, PCCI, and Dual-Fuel PCCI) on Engine Performance and Emission Characteristics in a Heavy-Duty Diesel Engine," Fuel 262:116436, 2020, doi:10.1016/j.fuel.2019.116436.

Goyal, H., Panthi, N., Houidi, M. Ben., AlRamadan, A., Badra, J., and Magnotti, G., "Performance Analysis and Incylinder Visualization of Conventional Diesel and Isobaric Combustion in an Optical Diesel Engine (submitted to SAE Naples)," SAE Technical Paper 21ICE-0056, 2021.

\section{Contact Information}

niraj.panthi@kaust.edu.sa

\section{Acknowledgments}

This paper is based on work supported by Saudi Aramco Research and Development Center FUELCOM program under Master Research Agreement Number 6600024505/01. FUELCOM (Fuel Combustion for Advanced Engines) is a collaborative research undertaking between Saudi Aramco and KAUST intended to address the fundamental aspects of hydrocarbon fuel combustion in engines, and develop fuel/engine design tools suitable for advanced combustion modes.

We would like to thank Prof. Sanghoon Kook and Dr Lingzhe Rao from the University of New South Wales (UNSW), Sydney, Australia for their assistance on FIV analysis.

\section{Definitions/Abbreviations}

$\begin{array}{ll}\text { aTDC } & \text { After Top Dead Center } \\ \text { BDC } & \text { Bottom Dead Center } \\ \text { BTE } & \text { Brake Thermal Efficiency } \\ \text { CLAHE } & \text { Contrast Limited Adaptive } \\ \text { CAD } & \text { Histogram Equalization } \\ \text { CDC } & \text { Crank Angle Degree } \\ \text { CFD } & \text { Conventional Diesel Combustion } \\ \text { CI } & \text { Computational Fluid Dynamics } \\ \text { CoV } & \text { Compression Ignition } \\ \text { DCEE } & \text { Coefficient of Variation } \\ & \text { Double Compression Expansion } \\ \text { DFT } & \text { Engine } \\ \text { Fuel MEP } & \text { Discrete Fourier Transform } \\ \text { FIV } & \text { Fuel Mean Effective Pressure } \\ \text { HCCI } & \text { Flame Image Velocimetry } \\ \text { HRR } & \text { Homogeneous Charge } \\ \text { LDV } & \text { Compression Ignition } \\ \text { ND } & \text { Heat Release Rate } \\ \text { NOx } & \text { Laser Doppler Velocimetry } \\ \text { PCP } & \text { Neutral Density } \\ \text { PIV } & \text { Nitric Oxides } \\ \text { PLIF } & \text { Peak Cylinder Pressure } \\ \text { PLII } & \text { Particle Image Velocimetry } \\ \text { PPC } & \text { Planar Laser Induced } \\ \text { PM } & \text { Fluorescence } \\ \text { PMP } & \text { Planar Laser Induced } \\ \text { RCCI } & \text { Incandescence } \\ & \text { Partially Premixed Combustion } \\ \text { Particulate Matter } \\ \text { Peak Motoring Pressure } \\ \text { Reactivity Controlled Compression Ignition } \\ \end{array}$




\section{Appendix}

Appendix A - In-cylinder pressure and heat release rate for baseline cases (using central injectors only)

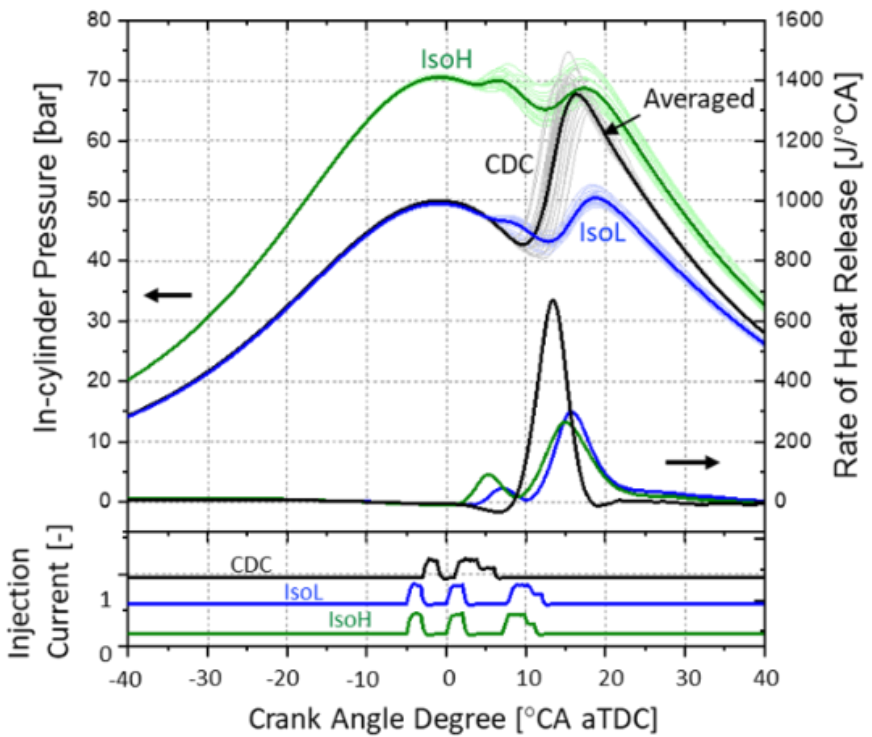

Figure A1. In-cylinder pressure, heat release rate, and the injector current signals for CDC, low-pressure isobaric (IsoL), and high-pressure isobaric (IsoH) combustion. This is adapted from [39]. 